\title{
Sustainable Health Care Management in the Greek Health Care Sector
}

\author{
Anastasios Sepetis \\ University of West Attica, Athens, Greece \\ Email: tsepet@yahoo.com
}

How to cite this paper: Sepetis, A. (2019) Sustainable Health Care Management in the Greek Health Care Sector. Open Journal of Social Sciences, 7, 386-402. https://doi.org/10.4236/jss.2019.712030

Received: November 26, 2019

Accepted: December 23, 2019

Published: December 26, 2019

Copyright (c) 2019 by author(s) and Scientific Research Publishing Inc. This work is licensed under the Creative Commons Attribution International License (CC BY 4.0).

http://creativecommons.org/licenses/by/4.0/

\begin{abstract}
The international health care system, as well as the Greek health care system under the current climate change problems and the sustainable development goals solutions just begin to understand the impact that environmental and social issues will have on health care services. Greek hospitals and the Greek health care system have the potential not only to adapt to climate change, but also in the process to promote social value, greater social equity and environmental health through sustainable development goals. At the same time, based on a different perspective, social responsibility, environmental management and governance are at the forefront of attention, not only as the most up-to-date characteristics of a hospital strategy, but also in relation to national and international economic policies aiming for better economic results for local communities and stakeholders. In other words, environmental, social and governance issues are today incorporated to sustainable hospital management and have already become part of the Greek Sustainable Health Care System. In this paper the literature review suggests that sustainable health care could be a driver of sustainability in the health care system and specifically in the Greek Hospitals. The empirical research analysis in the Greek hospitals recognized that in the recent years remarkable steps for environmental and social issues have been made. However, according to sustainable management theory, as this is referred in the paper, in order to achieve sustainability in the Greek health care system through sustainable health care management, is necessary to promote, rebuild and adapt the health care system to a concrete holistic sustainable health care management, which is supported and evaluated by the Greek Ministry of Health and the Greek health care market.
\end{abstract}

\section{Keywords}

Sustainable Development Goals, Sustainable Health Care, Sustainable Hospital, Environmental, Social, and Governance (ESG) Policies, 


\section{Introduction}

According to EU Greek HealthCare data in the 2017 Greece spends EUR 1.650 per capita on health care, over one-third less than the EU average. This is $8.4 \%$ of GDP but, in the context of a shrinking economy, health spending has declined significantly since 2009. Public expenditure on health is one area being contained as part of fiscal sustainability measures. Currently, 59\% of health spending is publicly funded, while out-of-pocket spending (35\%) is more than double the EU average [1]. Greece is now a country, where the need of re-orientation of health care financing is pressing. According to Economou, there is also a need to rethink and to promote a public debate on the health budget not as a financial burden, but as a developmental tool, with the need to address not only economic dimensions but also the welfare of citizens. In other words, resetting the social values underlying the health care system is a prerequisite for establishing a new paradigm for its sustainable development [2]. The 2030 agenda for Sustainable Development Goals is an opportunity for governments and the international community to renew their commitment to improving health as a central component of development [3]. The accompanying 17 sustainable development goals (SDGs) define the priority areas of action. 2 Goal 3 (to ensure healthy lives and promote wellbeing for all at all ages), with Target 3.8 on universal health coverage (UHC), emphasize the importance of all people and communities having access to quality health services without risking financial hardship [4]. These health services include those targeting individuals, such as curative care and population-based services, such as health promotion [5] [6]. Also from 2013 the Organization for Economic Co-operation and Development (OECD) opened the debate to "sustainable health care" [7].

The ANH (Alliance for Natural Health) first defined sustainable health care for its readers in the journal Nutrition Practitioner in 2006. "A complex system of interacting approaches to the restoration, management and optimization of human health that has an ecological base, that is environmentally, economically and socially viable indefinitely, that functions harmoniously both with the human body and the non-human environment, and which does not result in unfair or disproportionate impacts on any significant contributory element of the healthcare system" [8]. According to Weisz, in order to define "sustainable hospital", additional criteria should be introduced: 1) contribution to the preservation of nature by limiting resource use and other environmental pressures; 2) reduction of costs to the national economy; and 3) minimization of social burdens within and outside the hospital. "Sustainable decisions" should take all these dimensions into account together by evaluating different options also in terms of their side effects and long-term consequences [9]. Accordingly, a (more) sus- 
tainable development in the health care system setting is one in which services are improved in relation to the status quo for at least one of the Environmental, Social and Governance (ESG) factor dimensions without impacting negatively upon the other ones and the hospital efficiency [10].

The sustainable development goals (SDGs) are interdependent and integrated. The SDGs aim to impact all levels of society, reach across all sectors, embrace equity, inclusion, and universality, and operate in an ecosystem. Health care's percentage of GDP, as well as overall per capita spending on health care, varies widely between nations, and there are significant health inequalities within countries as well. According to McGain and Naylor (2014) there are still significant gaps in the evidence based on hospital sustainability. Assessments of environmental impacts and natural resource use begin to be produced, both at the level of individual hospitals and at the health system level. These make an important start, but still in many areas do not provide sufficiently detailed information to guide decision-making yet. There are many areas, where the interests of patients and the environment coincide, but others where tensions exist. Rising resource costs and climate change mitigation measures are likely to create an increasing stimulus for research on hospital sustainability [11].

The research question in this paper is how interested are environmental, social and governance issues for the health care system and specifically for the Greek health care system. Another question is if environmental, social and governance solutions should include social interventions that improve health, reduce environmental impacts and enhance the social value of stakeholders (employees, suppliers, customers, local communities, etc.) and at the same time earn financial gain for the Greek hospital and the Greek society.

In order to answer that questions, a literature review was designed to identify all the international and Greek academic articles that added new findings to the evidence based on "sustainable or green or environmental or social or ESG health care system and hospitals". The majority of the articles found are about the environmental impact in hospitals and the impact of climate change in the health care system. Less articles explain though, how the sustainable development policies and management incorporate in the health care system. Moreover, an empirical research takes place in this paper within Greek public and private hospitals, in order to investigate the environmental, social and governance issues and how to incorporate sustainable health care management in the Greek hospital management.

\section{The Environmental, Social and Governance Impacts in the Health Care System}

The environmental health impacts come in all shapes and sizes, ranging from pathogenic medical waste dumped in back of a rural clinic during a vaccination campaign. Although the proportion of individuals seeking medical treatment during a disaster is typically a small subset of the total number of persons af- 
fected, the additional burden on health care facilities can be significant [12]. Floods and wildfires also can require the evacuation of critical care patients, with attendant risks. When these extreme events are very large, they can affect the ability of health care systems to function properly and to care for patients with ongoing health issues that require medication or treatment. In cases where these events become significantly more frequent or intense, health facilities might need to add surge capacity to help them to manage such events without interrupting service [13]. The PESETA a EU JRC project in 2009 (Projection of Economic impacts of climate change in Sectors of the European Union based on bottom-up Analysis) was the first attempt to make a multi-sectoral assessment of the impacts of climate change in Europe for the 2011-2100 time horizon. In the health study of PASETA project I and II [14], exposure-response functions were combined with estimates of the future modelled climate, along with estimated changes in the population (size and age), to predict the likely consequences of climate change (2011-2100). In model runs without acclimatization, economic costs in current values were estimated at US $\$ 12.6$ billion to US $\$ 31.6$ billion a year by the 2020s using a value of statistical life metric, but US $\$ 1$ billion to US $\$ 4.2$ billion a year when acclimatization was included. The recent Climate Impact Research and Response Coordination for a Larger Europe (CIRCLE) study used a combination of global models: a computable general equilibrium model to project effects to 2060 and the AD-RICE model to project effects beyond 2060 [15]. Using a value of statistical life approach, they projected that the economic costs of heat-related deaths would increase from around US $\$ 100$ billion today to US $\$ 320$ billion in 2030 and US $\$ 670$ billion in 2050, with the highest costs in Europe and North America. The Daniella Paci model for PASETA project II in the 2014 estimated that the financial cost of climate change-attributable deaths will increase significantly over the next 90 years. At country level, the number of cases is expected to increase up to 1.091 additional cases per year, due to higher temperatures. Resource costs are calculated for both additional hospital admissions and additional cases of salmonellosis and campylobacteriosis. These costs, for each country, can grow up to $28.23 \mathrm{M} €$ (on average) at the end of the century [16].

WHO reacts to climate change and the environmental and social risk and suggests a framework to health care system, proposing national health care systems to express the principles, commitments and priorities of the organization with respect to the environmental and social policies [6]. In 2000, 27 representatives of the Canadian Coalition for Green Health Care ${ }^{1}$, some of Canada's largest health care associations and environmental groups, met in Ottawa at an environmental educational day, organized by the Canadian Association of Physicians for the Environment. The adoption by all components of Canada's health care system-public and private-of resource conservation and pollution prevention principles and effective environmental management systems lead to a sustaina1https://greenhealthcare.ca/ 
ble health system. The NHS Sustainable Development Unit (SDU) ${ }^{2}$, established in 2008, help organizations across health and care embed and promote sustainable development in order to reduce emissions, save money and improve the health of people and communities. At an environmental level this includes addressing issues such as energy, travel, waste, procurement, water, infrastructure adaptation and buildings. More broadly their work expands into the wider long term needs of the health system including adaptation of health service delivery, health promotion, tackling the wider determinants of health, corporate social responsibility and developing new sustainable models of care. The Health Care Without Harm (HCWH $)^{3}$ Europe is a non-profit European coalition of hospitals, healthcare systems, healthcare professionals, local authorities, research/academic institutions and environmental and health organizations. The Global Green and Healthy Hospitals network ${ }^{4}$ has more than 1200 members in 60 countries that represent the interests of over 36,000 hospitals and health centers. Many special green health care projects promote Green Hospital ${ }^{5}$ as one of the four initiatives of the Hospital 2020 movement.

\section{Implementing Environmental, Social and Governance Management Policies in the Health Care System}

It is common that CEOs in public hospitals that apply ESG management policies, contribute to the understanding of these problems, because hospitals comply with environmental or social legislation, focus on state aid social or environmental sanctions and increase or decrease hospitals' value in relation to reducing green or labors law fines, always compared to non-compliance with environmental or social laws and legislation. Moreover, the CEOs of public hospitals most often cite the following environmental, social and governance factor as the reasons they are pursuing ESG initiatives: 1) Saving money; 2) Increasing employee satisfaction and retention; 3) Managing risk and regulatory compliance; 4) Improving facility operations and pursuing performance excellence; 5) Demonstrating and reporting the environmental, corporate social responsibility and governance issue [10]. The CEOs and the shareholder management team in firms as well as private hospitals for the implementation of ESG management policies will not favor every public or voluntary ESG action, but only the measures that, in their best combination, increase the hospitals business value in the market, such as the optimal combination of the following indicators that have an impact on its operational management, investment and financial management, that factor are [17] [18] [19] [20]: 1) Margin Profit Increase: Better profit margin due to higher profit and lower operating costs for hospitals through improved ESG operating capability; 2) Long term License to operate: The expectation of a constant reduction in future environmental or social costs of hospitals opera${ }^{2}$ https://www.sduhealth.org.uk/policy-strategy/what-is-sustainable-health.aspx ${ }^{3}$ https://noharm-europe.org/content/europe/who-we-are

${ }^{4}$ https://www.greenhospitals.net/who-we-are/

5http://hospital2020.org/Agreenhospital.html 
tion, increased profitability and better protection against unexpected environmental accidents or social and governance problems further guarantee uninterrupted operation; 3) Promoting Good Will, Brand Name \& Reputation: Increasing the gross profit and attractiveness of health services to customers and creating new health services markets (more desirable environmental and social products and services for more stakeholders); 4) Enhancing capital investment for the development of new innovations (Capital Innovation): Development of new ESG innovations through research and hospitals development, which will provide a comparative advantage; 5) Enhancing capital investment in know-how and human skills development (Human Intellectual): Specialization and training of personnel in ESG management gives the hospital valuable human capital; 6) Ensuring stable, smooth and low interest rates (Good risk profile): Confidence in the capital market. Smaller and less systematic ESG risks and, if possible, "green" or "social" additional profit margins, bring better interest rates, premiums and easy access to money from health care providers such as banks, insurance companies, pension funds, European Union finance sustainable programs, etc.

Furthermore, CEOs of public and private hospitals see cost as the primary barrier to undertaking sustainable efforts, as some sustainability projects can be expensive. However, some well-planned programs can be implemented at no cost, and many projects can have short payback periods [21] [22]. For projects that require a lot of up-front investment, hospitals and health care systems are increasingly turning to alternative funding sources. These include: 1) Grants, rebates and donations: Many utilities for hospitals have grant or rebate programs that can help fund energy projects. Sustainability strategies are also attractive to potential donors, including individuals, organizations and businesses; 2) Sharedsavings agreements: Under shared-savings agreements, a third party agrees to finance, design and install energy projects, with the costs paid from energy savings that result from the projects; 3 ) Power purchase agreements: Under power purchase agreements, a third party owns, installs and operates a power-producing asset, such as a renewable energy source. In turn, the hospital agrees to purchase the power generated from the plant; 4) Carbon-emission offsets: A number of voluntary markets are available to sell carbon offsets and renewable energy credits. Hospitals can combine these various methods and other strategies to find creative ways to implement sustainability initiatives. Many hospitals and health care systems have foundation departments that can help write grant applications or solicit donations for sustainability projects. Health care leaders should explore various options and determine the appropriate solutions for their organization. Furthermore, if a hospital adopts the previous steps, it could also extend its actions and try to optimize the protection of the environment and society, through the following actions.

In a survey of NHS CEOs, the most needed changes for long-term sustainability are: "working with other groups/organizations", "changes to pathways and models of care" and the need to "improve awareness and understanding of sustainability 
throughout organizations" and "embed the practice as other issues gain priority in regards to cost-savings". Therefore performance standards are beginning to be implemented to integrate sustainability criteria into the organization [23]. In an ideal situation, solutions are sought that improve all dimensions. Hospitals and health care systems exist to serve their communities-not only to provide healthcare services, but to bolster the local economy and quality of life by hiring local workers and contractors, buying locally through purchasing agreements and building clinical facilities in neighboring communities. In addition to these benefits, sustainability also brings a variety of other benefits specific to the health care field: 1) With community health becoming a top priority for hospitals and care systems, many leaders are placing greater value on reducing pollution and creating a smaller environmental footprint; 2) Health care organizations are also increasingly pursuing lean approaches to become more efficient in various processes, a natural fit with sustainability efforts; 3 ) Some sustainability efforts, such as retro commissioning, can improve patient health by contributing to lower infection rates and fewer patient transfers [24].

According to health management organization the world's population continues to rapidly increase as well as grow older. To establish a Greek sustainable effective healthcare system over the long term and to make sustainable healthcare affordable for everyone, they also need technological and management innovations that both improve the quality of medical care and help save money.

\section{The Greek Sustainable Health Care System}

The following articles refer a sort literature review to the sustainable Greek health care system. Argiriou and co-authors performed an audit in offices and hospitals, which identified indoor air quality problems, due to outdoor air pollution, verified with local measurements of specific pollutants [25]. Moreover, Santamouris and others researchers have performed energy audits on 30 hospital buildings [26]. Furthermore, an energy audit of hospitals has been presented by Balaras et al., based on the air change rate measurement of operating rooms [27]. A review is presented by Kolokotsa of the hospitals' energy saving techniques [28]. Based on the above review, a significant number of hospitals are turning to the installation of renewable energy sources and advanced energy efficient technologies (photovoltaic, trigeneration and geothermal systems) to reduce their depend fossil fuels. For the hazardous medical waste unit generation rates (HMWUGR), Komilis and co-authors in 2012 were to calculate the (HMWUGR), in $\mathrm{kg}$ bed, using data from 132 health-care facilities in Greece. Based on nonparametric statistics, HMWUGR were statistically similar for the maternity and general hospitals, in both the public and private sector. The private maternity and general hospitals generated statistically more wastes compared to the corresponding public hospitals. The infectious/toxic and toxic medical wastes appear to be $10 \%$ and $50 \%$ of the total hazardous medical wastes generated by the public cancer treatment and university hospitals, respectively [29]. Zamparas 
and associate researcher in 2018 developed a multi-criteria model to examine the available procedures, techniques and methods of handling infectious waste in the large healthcare unit of University Regional General Hospital of Patras, Western Greece. The results indicated a very good value in environmental management criteria, due to the values obtained for the commitment towards the environmental policy standards and the waste management procedures. However, further improvements on staff awareness (such as development programs to enhance sensitivity) and more green purchasing suppliers, should be further addressed [30]. Moreover, Zamparas and Kalavrouziotis, in their 2018 results showed that more hospitals have an established Hazardous Medical Waste Management System, based on internal regulation of infectious waste management. The quantities of infectious wastes produced by the studied hospitals, expressed per day and bed (kg bed-1 day-1) were within the range illustrated both in Greek and International literature [31].

\subsection{EU Funding Program for Green Greek Hospitals}

The following paragraph provides some examples of EU funding program for environmental management policies in the Greek hospitals. The EU project "ehospital EMAS" aimed to demonstrate the use of EMAS (Eco Management and Audit Scheme as management tools) for developing an environmental action program in two hospitals in Athens and for establishing appropriate administrative structure. Then, it is worth noting that the hospital of "Metropolitan", which is a private hospital, implements an environmental management system and it is in the certification process of the standard EMAS. Additionally, a public hospital that implemented environmental management activities is the General Hospital of Voula "Asklipieio", which operates a system of environmental management standard EMAS [32].

Another EU project the Green@Hospital project was conceived to help hospitals to save energy through the most modern ICT technologies and ad-hoc new algorithms. To reach the ambitious goals, an EU consortium consisting of four hospitals, two research centers and five companies was put together and worked together since 2012, testing innovative solutions in real operating conditions. Four pilot hospitals, two research centers and five firms have worked together since 2012 testing innovative solutions in real operating conditions. Important savings have been reached exceeding the expectations and replicability has been verified, including the calculation of the Pay Back Time. The tested solutions are suitable to be easily replicated in other healthcare facilities reducing by $15.4 \%$ the energy consumption in the selected areas [33]. The Greek panther of the project Saint George Hospital in Chania, analyzed a building optimization and control (BOC) algorithm, which is implemented in the existing building energy management system (BEMS). The result of the project for the hospital was the achievement of the annual primary energy efficiency, which was almost $36 \%$ [34]. 


\subsection{Sustainable Health Care in the Greek Public Hospitals}

Some research evidence appears in the public health care group in Greece. The General Hospital of Kalamata has made moves aimed at adopting environmentally friendly policies and saving energy. In particular, it carried out a supply and installation of a solar thermal system on the hospital roof, which is used for space heating and hot water production including: 1) 226 solar panels; 2) 7 water heaters; 3) Heating water temperature compensation unit; 4) Hot water temperature control unit and Solar-powered remote control and remote control unit and other equipment. It is thus estimated that they save $€ 230,000.00$ annually, while carbon dioxide emissions decreased by 546.2 tones. Also they upgraded the building infrastructure through the bioclimatic upgrading project with the immediate aim of improving the energy efficiency of the hospital home building. The above was made possible by the application of waterproofing and dehumidifying energy-based ceramic paints on the facades of buildings and the replacement of waterproofing and the addition of thermal insulation to rooms. Furthermore, they installed a photovoltaic station in the courtyard of the hospital and a geothermal pump system. Moreover, they installed a medical oxygen production system with an estimated annual financial benefit of $€ 300,000$ [35]. The Papageorgiou General Hospital of Thessaloniki has been operating a High Performance Electricity and Thermal Energy Cogeneration Unit since 2016. The plant is a facility that generates electricity using an internal combustion engine consuming natural gas. Utilizing engine and exhaust heat, produces hot water, 1600 $\mathrm{KW}$ of electricity, representing $76 \%$ of peak demand and 1,400,000 Kcal/h of thermal power. This quantity is capable of heating $8-10$ four-storey houses in winter. In the summer the heat turns to cool. In this way, the hospital has managed to reduce electricity consumption by $37 \%$ saving $€ 600,000.00$ per year [36]. Management and employees of the General Hospital of Chalkida decided in 2012, recognizing the importance of the quality of environmental health, aimed to promote activities, where the quality of services provided and the satisfaction of patients and their visitors were combined with environmental protection. The Hospitals' policy aimed not only to align with relevant legislation and to prevent environmental pollution, but also to continuously improve the environmental impacts of the healthcare unit by monitoring and reducing all environmental pressures arising from the units' activities [37]. In 2014 the environmental management of the General Hospital of Lamia has become part of the modern management of the hospital, as it has already taken the form of implementing Environmental Management and Efficient Systems. The hospital counted its energy consumption, after recording data and observing its operations. Following that planned various actions in order to reduce its energy costs, save resources and improve the institutions' contribution to the environmental protection. For this reason, a number of actions were taken to achieve the objectives set: 1) a study was carried out to replace conventional fluorescent lamps with corresponding electronics; safety sensing limits for users-setting a significant percentage of lighting off (saving around $1.200 \mathrm{kw} / \mathrm{h}$ ); 2) a more "tight" and ra- 
tional use of water-cooled chillers, as well as particularly energy-intensive installations, was followed, always maintaining a level of comfort for patients, staff and visitors at normal levels; 3) Regarding Hospital Heating: The central surface building approximately covered its needs with Natural Gas. Since 2014, employees implemented the new Internal Hazard Waste Management Regulation of the Hospital. Implementation of the new regulation reduced weight of the hazardous medical waste production totaling $11.40 \%(4100.87 \mathrm{~kg})$ in the first eight months, while individually in the last months of July and August, the decrease was $15.31 \%$ and $16.82 \%$, respectively, compared to 2013. Recording the above, General Hospital of Lamia took part in the Facilities Management Awards 2014 competition and won the Gold award in the Energy management and certifications category [38]. The Sismanoglio General Hospital has in recent years changed boilers/network insulation and installed hot water solar collectors. In this way the saving is estimated by $30 \%$ of energy, i.e. $2,280,000 \mathrm{kwh}$ (th), while the replacement of petrol with gas reduced the energy cost by $20 \%$ [39]. A series of energy saving actions have taken place at the Thessaloniki General Hospital "Agios Pavlos". More specifically: 1) replacement of windows with new improved thermal properties, 2) replacement of low-efficiency incandescent in candescent lamps with more efficient fluorescent lamps, 3) installation of exhaust gas turbines on boiler gas to enhance the heat exchange between hot exhaust gas and water, 4) replacement of old burners with new multistage, dual fuel oil-gas burners and connection to the city's gas network to replace heating oil, 5) maintenance of air conditioning units. Cleaning and repairing of chiller filling, heat exchanger surfaces, air shutters, repairing and upgrading of heat insulation pipes [40]. The General Hospital of Grevena has implemented a series of actions that are estimated to have reduced energy consumption by $70 \%$ in water, by $50 \%$ in heating costs and by 35\% in electricity consumption in the period 2012-2016. These actions were related to informing staff on environmental issues and proper use of energy, timers and sensors were installed that regulated the operation of specific rooms' heating and lighting (e.g. air conditioning and heating of the administrative services automatically shut down when the spaces were closed), while all the floats in the water tanks and the sanitary facilities of the Hospital were changed. The General Hospital of Xanthi since 2010 covers its needs for natural gas heating, saving approximately $€ 350,000.00$ annually [41]. At the General Hospital of Alexandra the pharmacy is certified according to the quality standards. Concerted action aims to make the pharmacy not only energy autonomous, but also a standard ecological hospital pharmacy. The bioclimatic pharmacy, designed to specific specifications, utilizes alternative forms of energy, such as solar energy, manufactured with environmentally friendly building materials that at the same time insulate the home better for energy savings and protection against noise pollution. The use of recyclable materials in the construction of the pharmacy, as well as in everyday life enables the protection of the environment, as well as a change in the mentality of using cheap but harmful materials e.g. plastic bags. 


\subsection{Sustainable Health Care in the Greek Private Hospitals}

Some research evidence appears in the big private health care group in Greece. At Euroclinic Hospital in 2015, more than 20,000 tons of recyclables were collected. With the help of its staff and its environmental awareness, the hospital managed to save 665,000 tons of water and $85,055 \mathrm{kwh}$ of electricity, which is sufficient to meet the energy needs of a home for approximately 7.5 years. 347,000 trees were also "rescued". Athens Euroclinic is the first clinic in Greece and in Europe to be certified as "Patients' Friendly Hospital". The aim of the certification and adoption of the International Guidelines' Patients' Friendly Hospitals' is to develop best practices for the creation of an ideal patient-friendly environment for patients, relatives and attendants [42]. Since 2008, the Athens Medical Group and Vodafone have joined forces for the Vodafone Telemedicine Program. Utilizing medical excellence and cutting-edge technology, they enable more than 500,000 residents in 100 remote areas of Greece to have free access to high quality specialized health services. The Telemedicine Program is under the auspices of the Ministry of Health and the Ministry of Shipping and the Aegean. The Athens Medical Center Group, in an effort to contribute to the effort to protect the environment, has developed and implemented the Environmental Management System (ISO) according to ISO 14001 [43]. Also the YGEIA Group implements the certified Environmental Management System certified in accordance with the international standard ISO 14001. The YGEIA Group Corporate Responsibility Report 2016 was prepared in accordance with the guidelines of the International Organization for Global Reporting Initiative (GRI-G4 version). Also the Corporate Social Responsibility Report since 2015 encloses the Greek Sustainability Criteria Coverage Table and the GRI-G4 Indicator Coverage Table and ISO 26000. Only a small number of private hospitals in Greece perform social actions and not to a great degree. Some examples of Greek hospitals that have embraced CSR in their operation, is the private hospital "YGEIA", and in response to the request of the organization "Flame" has allowed a free radiation test for children, who suffer from cancer [44]. The IASO Group has distinguished itself by receiving four Corporate Social Responsibility Awards, while it constantly supports vulnerable social groups and significant actions taken by more than 20 NGOs and Associations through the provision of top quality healthcare services. One of IASO Group's main goals is to implement the "By your Side" program for the benefit of vulnerable social groups, by meeting major needs of citizens in practice. It actively supports NGOs, primarily those involved with children, women and families. Additionally, it provides humanitarian assistance to children in Africa in collaboration with the Patriarchate of Alexandria. Moreover IASO Group has been awarded the SALUS INDEX AWARDS 2019 Business Excellence Award for its cutting-edge and modern equipment and its intensive Corporate Social Responsibility activities [45]. Finally, it participates in medical missions of the international organization "Chain of Hope" in Mozambique and supports the various insurance funds with very high budget. The pe- 
diatric clinic "Mitera", has taken action in the Greek isolated province, in order to support vulnerable groups by providing preventive and diagnostic medical services with a view to updating the region's children in need [46].

\section{Results and Discussion}

Therefore, sustainable health care is an optimization task for Greek hospitals, to deliver their environmental, social and governance core and support services not only according to health care and health promotion quality criteria, but also according to criteria of economic efficiency, as well as social and environmental compatibility. According to the Greek literature review and empirical research, the Greek private and public hospitals have begun to invest systematically in the understanding of the environmental or social effects of hospitals. In the last years a significant part of the environmental footprint of public and private hospitals relates to environmental law-legislation and voluntary environmental tools in the management decisions involved in the Greek hospitals management. Moreover, there is a developed research base regarding devices and green technologies used within hospitals to reduce the environmental effects of direct hospital energy and water use. However, less is known about the labour, and other social factors that influence how health care professionals make an effective use of the resources. The empirical research found that there are no official data from Greek ministry of health or other official institutions to evaluate the environmental, social and governance impact of Greek hospitals. Empirical research also found a variability in the extent of the evidence based on environmental or social topics between public and private hospitals. The Greek public hospitals are investing and presenting the most in environmental impact and the private Greek hospitals are investing and reporting mostly on the social consequences. In addition, there is a gap in Greek sustainable hospital reporting that has not been published and evaluated properly, so that to make financial, environmental, social costs or revenue understood to financial stakeholders and health care market. It is worth mentioning that only one Greek private hospital has reported a GRI annual report. To fill that reporting gap, for instance the effects of environmental policies should be recorded in the financial statements of hospitals. For this reason, the scientific field of environmental accounting is reasonably included in the analysis of environmental management policies in the field of health. Environmental accounting seeks to provide financial documentation of the environmental impacts on the balance sheet and financial results of a hospital to transmit symmetric environmental information to the market in the context of competitive health service pricing [47]. The ESG management policies can be applied to any Greek hospital regardless of structure, type and geographic location. It is an idea, a philosophy by which all Greek hospitals should move forward to sustainable management policies and act within the framework of fair competition. Basically, the Greek ministry of health is an organization that must input, promote and evaluate the sustainable health care management to the 
Greek public and private hospitals and encourage them to achieve certain sustainable goals under fair competition. In addition, a Greek sustainable hospital, whose purpose is to provide health and medical services should implement ESG management policies in all its functions, in all its services, so as to promote and protect the society and the environment because of the pressure that exists for Greek Environmental, Social and Governance law-legislation and the Greek health care market that seeks to adopt a more environmental and socially responsible behavior.

\section{Conclusion}

Over the past years the health care system and specifically Greek hospitals tried to develop sustainable health care management policies, but the question still remains the same: "how to incorporate sustainable management and finance to the sustainable change of health care system?" Liaropoulos and Goranitis suggest that it is difficult to think of a more "political" issue than the source of financing health care. This fundamental, but rather overlooked, concept in the economics of health policy needs to be actively debated as sustainable development goals gain traction in post-2015 policy agenda [48]. The policymakers of the Greek health care system thinking strategically about incorporating environmental, social and governance (ESG) issues can help hospitals save resources, reduce cost, gain profit and become economically more efficient. Moreover ESG policy can reduce the per capita cost of health care system by reducing health care expenses; for example, spending less money on utilities, enhances hospitals' (i.e. Green energy, paperless) ability to free up resources for patient care. Hospitals and health care systems that accomplish truly sustainable initiatives reap benefits in multiple areas. Their efforts contribute to a healthier environment, improve the social value of public perception and can help their local communities. For instance the environmental health impact of hospitals should come as no surprise given the health sector's huge economic clout. In order sustainable hospitals and sustainable health care facilities to make progress in sustainable finance areas, it's important to take a practical, feasible approach that aligns with budget and finance considerations. Moreover, private hospitals' CEOs, who want to succeed in the market and in society, must through governance, protect the present and discount its future sustainable operation. When undertaking compulsory or voluntary environmental and social policies, when recording and reporting on its sustainable performance, a hospital is in theory seeking to limit uncertain future ESG situations and to systematically manage ESG risk. These "Green" or "Social" or "Ethics" business strategy of hospitals (that is, being different from its hospitals competitors) highlights it as a sustainable signal in the international and Greek market. Therefore, CEOs in the private hospitals and professional financial stakeholders seeking profit or excessively normal returns on their equity value derived from market preferences for sustainable policies must be convinced by theoretical and empirical research, for leveraging the integration of 
ESG policies into hospitals' business operations. The pursuit of profitability and the far-reaching returns from environmental and social management in a competitive Greek health care market is a critical point for the success of such business strategy. If environmental and social policy does not lead to an increase in the business value of the hospitals, the competitive health care market will not accept it as economically advantageous and the hospitals will be pressured and may eventually be out of the health care market. For this reason the Greek ministry of Health or other official institutions play a crucial role in the evaluation of ESG factors in Greek hospitals, and seek to promote and report the sustainable performance of Greek hospitals each year in the Greek health care market. Sustainable health care system requires a strong link between environmental, social and governance of hospitals and sustainable development goals. Moreover, the sustainable development goals consider how we can live today without causing irreversible change that will threaten the lives and health of future generations. Incorporating environmental, social and governance management policies in the Greek hospitals helps us take a holistic view of all activities of the Greek health care system.

\section{Conflicts of Interest}

The author declares no conflicts of interest regarding the publication of this paper.

\section{References}

[1] EU 2017 (2017) State of Health in the EU Greece Country Health Profile. https://ec.europa.eu/health/sites/health/files/state/docs/chp_gr_english.pdf

[2] Economou, E., et al. (2015) The Impact of the Economic Crisis on the Health System and Health in Greece. In: Maresso, A., et al., Eds., Economic Crisis, Health Systems and Health in Europe: Country Experience, WHO/European Observatory on Health Systems and Policies, Copenhagen.

[3] Blanc, L.D. (2015) Towards Integration at Last? The Sustainable Development Goals as a Network of Targets. DESA Working Paper No. 141. United Nations Department for Economic and Social Affairs, New York. http://www.un.org/esa/desa/papers/2015/wp141_2015.pdf

[4] United Nations (2015) Transforming Our World: The 2030 Agenda for Sustainable Development. Seventieth United Nations General Assembly, New York, 25 September 2015, 1-35.

http://www.un.org/ga/search/view_doc.asp?symbol=A/RES/70/1\&Lang=E

[5] WHO (2013) The World Health Report. Health Systems: Improving Performance. World Health Organization, Geneva. http://www.who.int/whr/2000/en/whr00_en.pdf

[6] WHO (2017) Environmentally Sustainable Health Systems: A Strategic Document. http://www.euro.who.int/_data/assets/pdf_file/0004/341239/ESHS_Revised_WHO _web.pdf?ua $=1$

[7] Kumar, A. and Evetovits, T. (2014) What Is the "Fiscal Sustainability of Health Systems"? 3rd Meeting of the Joint DELSA/GOV Network on Fiscal Sustainability of Health Systems, Paris, 24-25 April 2014. 
[8] Alliance for Natural Health (2008) Sustainable Healthcare-Working towards the Paradigm Shift.

https://www.anhinternational.org/wp-content/uploads/old/files/100617-Sustainable Healthcare_White-Paper.pdf

[9] Weisz, U., Haas, W., Pelikan, J.M. and Schmied, H. (2011) Sustainable Hospitals: A Socio-Ecological Approach. GAIA, 20, 191-198. https://www.oekom.de/gaia https://doi.org/10.14512/gaia.20.3.10

[10] Sepetis, A. (2009) Environmental and Sustainable Management in Public Health. Papazisis Publications.

[11] McGain, F. and Naylor, C. (2014) Environmental Sustainability in Hospitals-A Systematic Review and Research Agenda. Journal of Health Services Research \& Policy, 19, 245-252. https://doi.org/10.1177/1355819614534836

[12] Hess, J.J., Heilpern, K.L., Davis, T.E. and Frumkin, H. (2009) Climate Change and Emergency Medicine: Impacts and Opportunities. Academic Emergency Medicine, 16, 782-794. https://doi.org/10.1111/j.1553-2712.2009.00469.x

[13] Banks, L.L., Shah, M.B. and Richards, M.E. (2007) Effective Healthcare System Response to Consecutive Florida Hurricanes. American Journal of Disaster Medicine, 2, 285-295. https://doi.org/10.5055/ajdm.2007.0038

[14] Watkiss, P., Horrocks, L., Pye, S., Searl, A. and Hunt, A. (2009) Impacts of Climate Change in Human Health in Europe. PESETA-Human Health Study, EUR 24135EN. https://ec.europa.eu/jrc/en/peseta/peseta-i-results

[15] OECD (Organisation for Economic Co-operation and Development) (2015) Modelling the Economic Consequences of Climate Change. The Economic Consequences of Climate Change, OECD, Paris.

[16] Paci, D. (2014) Human Health Impacts of Climate Change in Europe. EU JRC PASETA II.

https://publications.jrc.ec.europa.eu/repository/bitstream/JRC86970/lfna26494enn. pdf

[17] Porter, M.E. and Kramer, M.R. (2006) Strategy \& Society: The Link between Competitive Advantage and Corporate Social Responsibility. Harvard Business Review, 84, 78-92.

[18] Epstein, M.J. (2008) Introduction: Improving Social and Financial Performance in Global Corporations. In: Making Sustainability Work. Best Practices in Managing and Measuring Corporate Social. Environmental and Economic Impacts, Taylor \& Francis Group, New Delhi, 19-32. https://doi.org/10.4324/9781351280129-1

[19] Sepetis, A., Pierrakos, C. and Goula, A. (2009) Financial Assessment of Environmental Management Policies in the Operation of Hospitals. 21 st National Congress of the European Union Decision Making in Health Systems, Athens, 28-29 May 2009.

[20] Schaltegger, S., Lüdeke-Freund, F. and Hansen, E.G. (2012) Business Cases for Sustainability the Role of Business Model Innovation for Corporate Sustainability. International Journal of Innovation and Sustainable Development, 6, 95-119. https://doi.org/10.1504/IJISD.2012.046944

[21] Delmas, M. and Blass, V.D. (2010) Measuring Corporate Environmental Performance: The Trade-Offs of Sustainability Ratings. Business Strategy and the Environment, 19, 245-260. https://doi.org/10.1002/bse.676

[22] Karliner, J. and Guenther, R. (2011) Global Green and Healthy Hospitals. Health Care without Harm (HCWH).

[23] Ling, T., Pedersen, J., Drabble, S., Celia, C. Bereton, L. and Tiefensee, C. (2012) 
Sustainable Development in the National Health Service (NHS). National Health Service Sustainable Development Unit.

[24] Jameton, A. and Pierce, J. (2001) Environment and Health: 8. Sustainable Health care and Emerging Ethical Responsibilities. Canadian Medical Research Association, 164, 365-369.

[25] Argiriou, A. and Asimakopoulos, D. (1994) On the Energy Consumption and Indoor Air Quality in Office and Hospital Buildings in Athens. Energy Conversion and Management, 35, 385-394. https://doi.org/10.1016/0196-8904(94)90097-3

[26] Santamouris, M., Dascalaki, E., Balaras, C., Argiriou, A. and Gaglia, A. (1994) Energy Performance and Energy Conservation in Health Care Buildings in Hellas. Energy Conversion and Management, 35, 293-305.

https://doi.org/10.1016/0196-8904(94)90062-0

[27] Balaras, C.A., Dascalaki, E. and Gaglia, A. (2007) HVAC and Indoor Thermal Conditions in Hospital Operating Rooms. Energy and Buildings, 39,454-470.

https://doi.org/10.1016/j.enbuild.2006.09.004

[28] Kolokotsa, D.T., Tsoutsos, S. and Papantoniou, A. (2012) Energy Conservation Techniques for Hospital Buildings. Advances in Building Energy Research, 6, 159-172. https://doi.org/10.1080/17512549.2012.672007

[29] Komilis, D., Fouki, A. and Papadopoulos, D. (2012) Hazardous Medical Waste Generation Rates of Different Categories of Health-Care Facilities. Waste Management, 32, 1434-1441. https://doi.org/10.1016/j.wasman.2012.02.015

[30] Zamparas, M. and Kalavrouziotis, I.K. (2018) Healthcare Waste Management in Greece. The Example of Health Region of Western Greece, Peloponnese, Epirus and Ionian Islands. Global Nest Journal, 20, 96-102. https://doi.org/10.30955/gnj.002338

[31] Zamparas, M., Kapsalis, V.C., Kyriakopoulos, G.L., Aravossis, K.G., Kanteraki, A.E., Vantarakis, A. and Kalavrouziotis, I.K. (2019) Medical Waste Management and Environmental Assessment in the Rio University Hospital, Western Greece. Sustainable Chemistry and Pharmacy, 13, Article ID: 100163. https://doi.org/10.1016/j.scp.2019.100163

[32] E-Hospital EMAS (2006) EMAS Implementation in Hospitals Using LIFE04 ENV/ GR/00014 Information Systems e-Hospital EMAS Popular Report.

http://ec.europa.eu/environment/life/project/Projects/index.cfm?fuseaction=search. $\underline{\text { dspPage\&n_proj_id }=2744 \& \text { docType }=\text { pdf }}$

[33] EU (2015) Green Hospital Making Hospital Healthy and Green. https://ec.europa.eu/digital-single-market/en/content/greenhospital-making-hospit als-healthier-and-greener

[34] Papantoniou, S., Kolokotsa, D. and Kalaitzakis, K. (2015) Building Optimization and Control Algorithms Implemented in Existing BEMS Using a Web Based Energy Management and Control System. Energy and Buildings, 98, 45-55. https://doi.org/10.1016/j.enbuild.2014.10.083

[35] General Hospital of Kalamata (2017) Kalamata Hospital Brochure Kalamata Hospital-The First Green Hospital in the Country.

http://www.nosokomeiokalamatas.gron

[36] General Hospital of Papageorgiou (2017) Environmental Awareness. https://www.papageorgiou-hospital.gr/wp-content/uploads/2018/06/apologismos_2 016.pdf

[37] Sepetis, A. (2012) The Environmental Management Policy in the General Hospital of Chalkida. General Hospital of Chalkida CEO Report to Health Care Ministry. 
[38] Sepetis, A. (2014) The Environmental Management Policy in the General Hospital of Lamias. General Hospital of Lamias CEO Report to Health Care Ministry.

[39] Ladopoulos, G. (2017) Energy Saving on E/M Buildings Installations Practical Applications-Perspectives.

http://library.tee.gr/digital/m2414/m2414_ladopoulos.pdf

[40] Hliopanou, E., Giama, E. and Papadopoulos, A.M. (2011) Energy Saving and Environmental Management in Hospitals: Implementation at Thessaloniki General Hospital “AGIOS PAVLOS”.

http://www.conferences.gr/fileadmin/ARENEP/2011/content/presentations/ARENE P_2011_Hliopanou.pdf

[41] Babalides, A. (2010) Actions of Installing SINTHIA Units in the General Hospital of Xanthi. Xanthi Hospital Report.

[42] Euroclinic Hospital (2018) Corporate Responsibility Report Recovered. https://www.euroclinic.gr/about/quality-enviroment/

[43] Athens Medical Center Group (2018) Corporate Responsibility Report Recovered. https://www.iatriko.gr/el/content/csr-0?cl=609

[44] Ygeia Health Group (2018) Corporate Responsibility Report Recovered. https://www.hygeia.gr/hygeia/etaitiki-koinoniki-eythyni/

[45] IASO Group (2018) Corporate Responsibility Report. https://www.iaso.gr/en/iaso/corporate-social-responsibility/print

[46] Mitera Hospital (2018) Corporate Responsibility Report Recovered. https://www.mitera.gr/ypeythynotita-gia-tin-koinonia/

[47] Sepetis, A. and Kada, E. (2009) Environmental and Sustainable Accounting as a Key Indicator for the Environmental Efficiency of Hospital. 11 th International Conference on Environmental Science and Technology, Chania, Greece, 3-5 September 2009.

[48] Liaropoulos, L. and Goranitis, I. (2015) Health Care Financing and the Sustainability of Health Systems. International Journal for Equity in Health, 14, 80. https://doi.org/10.1186/s12939-015-0208-5 